ISSN: $1679-3013$

D.O.I.: 10.5914/1679-3013.2013.0096

\title{
CARACTERIZAÇÃO SEDIMENTOLÓGICA E GEOQUÍMICA DO APICUM DO SISTEMA ESTUARINO DO RIO ITAPESSOCA, GOIANA, PERNAMBUCO, BRASIL
}

\begin{tabular}{l} 
Recebido em: julho/2013 \\
\hline Aceito em: agosto/2013 \\
\hline
\end{tabular}

\author{
Thaís de Santana OLIVEIRA ${ }^{1}$ \\ Roberto Lima BARCELLOS ${ }^{1}$
}

\section{RESUMO}

O presente estudo caracterizou o apicum do sistema estuarino do Rio Itapessoca em Goiana, Pernambuco, por meio da análise da distribuição sedimentar atual. Para isso, foram realizadas análises granulométricas e dos conteúdos de matéria orgânica total e carbonato biodetrítico, correlacionando-os aos condicionantes locais. E caracterizou-se a composição isotópica de carbono $\left(\delta^{13} \mathrm{C}\right)$ e nitrogênio $\left(\delta^{15} \mathrm{~N}\right)$ da matéria orgânica contida nos sedimentos superficiais de 11 amostras coletadas. Os resultados obtidos foram homogêneos e indicaram sedimentos arenosos, de diâmetro médio areia fina $(2,00-3,00 \varphi)$, predominando sedimentos moderadamente a pobremente selecionados e com baixos conteúdos de lama. Observaram-se diferenças sutis entre as amostras localizadas próximas ao canal do Rio Itapessoca (estações 7-11), com maiores teores de carbonatos, lamas e matéria orgânica, e as amostras localizadas na porção

sedimentos arenosos estéreis. Os teores de carbono orgânico e nitrogênio também se apresentaram muito baixos $(0,19-0,62 \% \mathrm{C}$ e $0,003-0,031 \% N$ ), porém com leve aumento em duas amostras nas proximidades do manguezal $(0,38$ e $0,62 \% C)$. A matéria orgânica sedimentar, para a razão isotópica $\delta^{13} \mathrm{C}$, indicou ser de origem mista tendendo a marinha $(-22,5$ a $-19,3 \%$ PDB $)$, influenciada pelo aporte de água estuarino (-20,0\%oPDB). A razão isotópica $\delta^{15} \mathrm{~N}$ apresentou um comportamento particular para a área. Os percentuais de matéria orgânica total $(2,43$ a $5,40 \%)$ e carbonato biodetrítico $(1,7$ a $7,7 \%)$ mostraram baixa concentração, sendo os valores mais elevados relacionados com a proximidade do rio e nos locais com maior quantidade de lama nos sedimentos. Tais características dos dados atuais foram similares aos poucos trabalhos anteriores realizados em áreas de apicum.
\end{abstract} mais continental (estações 1-6) compostas de

Palavras chaves: planície hipersalina, mangue, sedimento, matéria orgânica.

\section{ABSTRACT}

This study characterized the salt flat of the Itapessoca River Estuarine System in Goiana, Pernambuco, by mean the analysis of modern sedimentary distribution. The employed parameters for this were the grain size, carbonate contents and the elemental and isotopic sedimentary organic matter analysis (C, N, $\left.\delta^{13} \mathrm{C}, \delta^{15} \mathrm{~N}\right)$, correlating this to local conditions in 11 surface sediments samples. The results were similar and composed of homogeneous sandy sediments, in diameter $(2.00-3.00 \varphi)$, prevailing moderately to poorly sorted lithoclastic sediments and low mud contents. Subtle differences were observed between samples located adjacent to the River Itapessoca main channel (stations 7-11), with higher concentrations of carbonates, mud, and organic matter; and the samples located in the salt marsh (stations 1-6) composed by sterile sandy sediments. The organic carbon and total nitrogen also show very low contents $(0.19$ to $0.62 \% \mathrm{C}$ and 0.003 to $0.031 \% \mathrm{~N}$ ), but with a slight increase in two samples near to mangrove $(0.38$ and $0.62 \% \mathrm{C})$. The sedimentary organic matter, for the isotopic ratio $\delta^{13} \mathrm{C}$, were from mixed origin tending to estuarine character ( -22.5 to $-19.3 \%$ oPDB), influenced by the contribution of estuarine waters (-20.0\%०PDB). The isotope ratio $\delta 1^{5} \mathrm{~N}$ showed a particular behavior for the area. The contents of total organic matter (2.43 to $5.40 \%)$ and calcium carbonate $(1.7$ to $7.7 \%)$ showed a low concentration, being the higher values associated with the proximity of the estuary and in the places with a greater amount of muddy sediments. These current data overall characteristics were similar to the scarce previous researches in salt-flat environment.

Key words: salt flat, mangroves, sediment, organic matter. 
OLIVEIRA, T. S.; BARCELLOS, R. L. Caracterização sedimentológica e geoquímica do apicum do sistema estuarino do Rio Itapessoca, Goiana - Pernambuco.

\section{INTRODUÇÃO}

Ambientes de sedimentação constituem unidades espaciais nas quais parâmetros físicos, químicos e biológicos condicionam o desenvolvimento de um corpo sedimentar e são suficientemente constantes para formar um depósito característico (Boggs, 1995). Os sedimentos depositados em áreas costeiras são resultantes da mistura entre o aporte de material terrígeno continental e os sedimentos autóctones, principalmente de origem biogênica, de plataformas continentais (MASSELINK; HUGHES, 2003). Estes depósitos sedimentares guardam em si registros da história evolutiva desse ambiente de transição e de seu comportamento atual, fornecendo parâmetros para a compreensão dos processos que nele ocorrem e de suas relações ecológicas (SUGUIO, 2003).

De acordo com Hansen (1959), os principais componentes que constituem os sedimentos são a fração inorgânica (minerais primários e secundários) e o húmus (constituinte secundário e, no geral, proporcionalmente menor) que compreende material dissolvido de origem orgânica e biodetritos. Os constituintes orgânicos e a distribuição do húmus são bastante sensíveis aos diversos fatores que condicionam os processos de deposição, assumindo a matéria orgânica, portanto, um caráter esclarecedor quando combinada com algumas das propriedades composicionais dos sedimentos (BADER, 1955).

Os estudos sobre a matéria orgânica sedimentar permitem avaliar condições ambientais de áreas sedimentares propiciando análises sobre as condições naturais da área e inferências sobre a ação antrópica nas mesmas. A associação das concentrações com a distribuição sedimentar e com a origem do material orgânico propicia melhor compreensão do processo de sedimentação atual e dos diferentes fatores que interferem no processo, tanto no tempo quanto no espaço.

As características referentes à textura e composição dos sedimentos podem, sobretudo, integrar estudos que visem compreender as tendências naturais do ambiente pesquisado $e$, assim, auxiliar em análises ambientais. Desta forma, os parâmetros granulométricos constituem um bom instrumento para avaliação da hidrodinâmica nos fundos de ambientes marinhos e costeiros de transição, de acordo com Pettijohn (1975).

O manguezal é um ecossistema costeiro, de transição entre os ambientes terrestres e marinhos, característicos de regiões tropicais e subtropicais, sujeitos ao regime das marés e que margeiam grande parte dos estuários nas áreas litorâneas (Schaeffer-Novelli, 1995). Estão associados também às margens de baías, enseadas, barras, lagunas e reentrâncias costeiras, onde haja encontro de água doce com a do mar, ou diretamente expostos à linha da costa. São sistemas funcionalmente complexos, altamente resilientes e resistentes. A cobertura vegetal constitui-se de espécies lenhosas típicas, além de micro e macro algas que se instalam em substratos de vasa de formação recente, de pequena declividade, adaptadas à flutuação de salinidade (SCHAEFFER-NOVELLI, 1995; 1999).

Coelho-Jr e Schaeffer-Novelli (2000) citam como funções e serviços prestados pelo manguezal: fonte de matéria orgânica, constituindo a base da cadeia trófica; área de abrigo, reprodução, desenvolvimento e alimentação de espécies marinhas, estuarinas, límnicas e terrestres, além de pouso de aves migratórias; manutenção da biodiversidade da região costeira; filtro de poluentes e sedimentos; fonte de recreação e lazer; proteção da linha de costa.

No Brasil, tal ecossistema ocorre desde Oiapoque, no Estado do Amapá, até os sistemas lagunares da cidade de Laguna, em Santa Catarina. A costa brasileira apresenta seis espécies típicas de mangue, pertencentes a três gêneros distintos: Rhizophora mangle, Rhizophora harisonii, Rhizophora racemosa, Avicennia schaueriana, Avicennia germinans e Laguncularia racemosa.

Devido ao fato de estarem os manguezais na faixa intermareal, em algumas áreas podem vir a ocorrer condições de hipersalinidade do sedimento, sendo resultado da interação entre períodos de inundação e secas extremas, causando acúmulos de sal que excedem a tolerância dos mangues e arbustos halófitos (Pellegrini, 2000). 
OLIVEIRA, T. S.; BARCELLOS, R. L. Caracterização sedimentológica e geoquímica do apicum do sistema estuarino do Rio Itapessoca, Goiana - Pernambuco.

Essas áreas banhadas somente pelas marés de sizígia são definidas como apicum, palavra de origem tupi que significa brejo de água salgada (Nascimento, 1993); e de acordo com Schaeffer-Novelli (1999), é parte integrante do ecossistema manguezal. Pode-se dizer que a formação dos apicuns depende, entre outros fatores, da amplitude das marés, da granulometria do sedimento, topografia e das interações geoquímicas (BALTZER, 1982 apud PELLEGRINI, 2000). Por sua vez, Cintrón et al. (1980) descreveram um esquema da formação de apicuns em zonas áridas a partir da evolução morfológica dos manguezais, na qual a sucessão ecológica das espécies de mangue reduziria a frequência de inundação pelas preamares nas partes internas do bosque, e consequentemente, aumentando a salinidade.

Para Maciel (1991), apicum ou salgado, ocorre na porção mais interna do manguezal, na interface médio/supra litoral, raramente em pleno interior do bosque. $\mathrm{E}$ análises realizadas por Nascimento (1993 apud SCHAEFFER-NOVELLI, 1999) concluíram que a salinidade influencia a distribuição dos organismos no apicum, atuando como fator limitante. A salinidade está condicionada pela topografia, frequência de inundação e drenagem terrestre, podendo variar nas diferentes estações do ano (NASCIMENTO-FILHO, 2007 e COELHO-Jr, no prelo).

Pellegrini (2000), destaca que o apicum tem função de abrigo para comunidades de caranguejos que ficam entocadas no sedimento durante os períodos de seca e atua como reservatório de nutrientes, no contexto do ecossistema manguezal, mantendo em equilíbrio os níveis de salinidade. O mesmo autor observa ainda que as características climáticas exercem maior influência sobre o apicum do que sobre o bosque de mangue, devido à menor frequência de inundação pelas marés e à proteção exercida pelo bosque.

Estudos específicos sobre os apicuns encontram-se em fase inicial, pois estão sempre associados a pesquisas relacionadas a manguezais ou mapeamento de zona costeira, apesar de serem encontrados associados a manguezais desde a Ilha de Santa Catarina, até o Estado do Pará.

Trabalhos que possuem como foco principal o apicum tratam da sua importância, seja para o ecossistema manguezal (NASCIMENTO, 1993), como para a sociedade (Jesus, 2008). Abordam sua relação como local para a carcinicultura (CREPANI; MEDEIROS, 2003; SANTOS, 2005). Realizam análise espaço temporal do ambiente (JESUS; HADLICH, 2009; HADLICH; UCHA, 2009; SANTANA et al., 2010). E o caracterizam (SANTOS et al., 1996; SCHAEFFERNOVELLI, 1999; SUSILO, 2005; HADLICH; UCHA, 2009), em estudos granulométricos do sedimento (PELLEGRINI, 2000; HADLICH et al., 2008), além de micro-topografia, salinidade e caracterização vegetal da área (PELLEGRINI, 2000; SIQUEIRA, 2009). Dentre os trabalhos citados, apenas Pellegrini (2000), determinou teores de matéria orgânica e de carbonatos e Nascimento (1993), estudou apenas o primeiro parâmetro.

O estudo dos apicuns é de grande valor, pois são locais de interesse econômico e que vem sofrendo eminente pressão (construção de tanques para carcinicultura e ocupação urbana, etc.), mesmo sendo considerado como Área de Preservação Permanente e Terreno de Marinha, pelas leis vigentes, como feição associada ao ecossistema manguezal.

Diante do exposto, a presente pesquisa destaca-se devido à carência de estudos neste tipo de ambiente, com características muito particulares e ainda pouco conhecidas, em especial, com relação ao comportamento de sua dinâmica sedimentar e composição geoquímica dos sedimentos superficiais.

A análise das características sedimentares, como a granulometria, associados à utilização de quimioindicadores ambientais, como a matéria orgânica sedimentar, constituem ferramentas das mais confiáveis e de resultados promissores em estudos da zona costeira e têm sido executados há décadas em várias áreas do globo (BADER, 1955; ROMANKEVICH, 1984; MEYERS, 1997; LAMB et al., 2006). Sendo também aplicados com sucesso em estudos realizados na costa do Estado de São Paulo (MAHIQUES, 1995; LIMA, 2000; BARCELLOS, 2000; RODRIGUES et al., 2003; BARCELLOS, 2005; BARCELLOS et al., 2005; BARCELLOS; FURTADO, 2006; FREITAS et al., 2008; BARCELLOS et al., 2009) e praticamente inéditos na região costeira de Pernambuco (BARCELLOS et al., 2011; Marcondes, 2009). 
OLIVEIRA, T. S.; BARCELLOS, R. L. Caracterização sedimentológica e geoquímica do apicum do sistema estuarino do Rio Itapessoca, Goiana - Pernambuco.

Assim, este trabalho tem como objetivo geral caracterizar a planície hipersalina, apicum, do estuário do Rio Itapessoca, Goiana, litoral norte de Pernambuco, por meio da análise da distribuição sedimentar atual (granulometria e geoquímica dos sedimentos superficiais).

Quanto aos objetivos específicos, tem como enfoque descrever a distribuição granulométrica, matéria orgânica total e teores de carbonato biodetrítico, correlacionando-os aos condicionantes locais; e caracterizar a composição isotópica da matéria orgânica contida nos sedimentos superficiais.

\section{ÁREA DE ESTUDO}

\section{O Município de Goiana}

O município de Goiana está localizado na mesorregião Mata e na Microrregião Mata Setentrional do Estado de Pernambuco, limitando-se a norte com o estado da Paraíba, a sul com Itaquitinga, Igarassu, Itapissuma e Itamaracá, a leste com o Oceano Atlântico e a oeste com Condado e Itambé.

A área municipal ocupa $492,1 \mathrm{~km}^{2}$ e representa $0,50 \%$ do estado de Pernambuco, onde as estruturas geológicas estão caracterizadas por cinco unidades: Formação Barreiras, Gramame, Depósitos Quaternários Marinhos, Formação Maria Farinha e Formação Beberibe (CPRH, 2003). $\mathrm{E}$ as feições do relevo do município são constituídas pela presença de Tabuleiros Costeiros e Planície Costeira, podendo ser observados restingas, mangues e dunas (CPRM, 2005).

O clima do município é quente e úmido, onde as temperaturas anuais são constantes em torno de $27^{\circ} \mathrm{C}$ (BARLETTA; COSTA, 2009). A precipitação média anual é de $1.634 \mathrm{~mm}$, podendo chegar a $2.000 \mathrm{~mm}$ aproximadamente (CPRM, op. cit.).

O município de Goiana encontra-se inserido nos domínios das Bacias Hidrográficas dos rios Goiana, Itapessoca, Botafogo-Arataca e Micro-Bacias Litorâneas; sendo as duas primeiras bacias as que ocupam maior área e assim exercem maior influência local ( $\mathrm{CPRH}$, op. cit.).

Adjunto à Ilha de Itapessoca, o Sistema Estuarino do Rio Itapessoca resulta da confluência de vários rios de pequena dimensão que nascem na vertente dos tabuleiros localizados ao norte e a oeste da citada ilha. Dentre os tributários do Itapessoca destacam-se os rios Sirigi, Ibeapicu, Carrapicho, Catuama e Guariba, este último tendo à sua margem esquerda a vila de Tejucopapo ( $\mathrm{CPRH}$, op. cit.), todos de drenagem exorréica, onde o regime das chuvas é bem distribuído propiciando uma rede fluvial perene (CONDEPE, 1980).

\section{Sistema Estuarino do Rio Itapessoca}

A área estuarina do Rio Itapessoca totaliza cerca de $40 \mathrm{~km}^{2}$, é a terceira em extensão no Estado de Pernambuco e a segunda no município de Goiana, e está inserida na Área de Proteção Ambiental de Santa Cruz. Abriga flora e fauna variadas, constituindo, juntamente com a área estuarina do Rio Goiana, importante fonte de sustento das comunidades urbanas e rurais circunvizinhas ( $\mathrm{CPRH}$, op. cit.).

O manguezal, por sua vez, está presente em todo estuário, sendo caracterizado pelas espécies Laguncularia racemosa, Rhizophora mangle, Avicenia sp. e Conocarpus erectus; a última ocorrendo com pouca frequência, sendo considerada por muitos autores como espécie de transição. A fauna está representada pelo aratu do mangue, chama-maré, ostra do mangue, guaiamum, caranguejo uçá e siris (SILVA, 2003).

Vale ressaltar que, de acordo com CPRH (2003), o manguezal da área foi pressionado, do lado do continente (em Tejucupapo e Catuama), com vistas à instalação de empreendimentos de carcinicultura, que alteram de forma significativa as características desse ecossistema. Atualmente, está instalada na Ilha de Itapessoca uma fábrica de cimento e projetos de ostreicultura, realizado pela colônia de pescadores locais.

Associada ao ecossistema manguezal, a feição apicum faz parte do sistema estuarino do Rio Itapessoca, sendo caracterizado por relevos mais elevados, em grande parte desprovida de vegetação vascularizada, ou abrigando uma vegetação herbácea. 
OLIVEIRA, T. S.; BARCELLOS, R. L. Caracterização sedimentológica e geoquímica do apicum do sistema estuarino do Rio Itapessoca, Goiana - Pernambuco.

No referido estuário, apicuns são encontrados nas bordas dos mangues, e no interior do bosque. E, de acordo com Santana et. al (2011), na análise espaço temporal de imagens, utilizando técnicas de sensoriamento remoto em três períodos (1988, 1997 e 2006), os apicuns mostraram um aumento significativo devido a processos de erosão, onde o material remobilizado à montante acaba assoreando os apicuns. Porém, há áreas em que o mesmo diminui em virtude da colonização da vegetação de mangue.

\section{METODOLOGIA}

\section{Atividades de campo}

As 11 amostras de sedimentos superficiais foram coletadas, em condições de sizígia, no dia 27 de setembro de 2011, na qual as posições dos pontos foram definidas e referenciadas por meio de um GPS.

De cada amostra total coletada com auxílio de uma colher de alumínio, cerca de $200 \mathrm{~g}$ foram acondicionados em sacos plásticos, etiquetados, para a realização das análises granulométricas, da matéria orgânica total e de carbonato biodetrítico em laboratório. Também foram analisados $\mathrm{C}$ e $\mathrm{N}$ elementares e razões isotópicas de carbono $\left(\delta^{13} \mathrm{C}\right)$ e nitrogênio $\left(\delta^{15} \mathrm{~N}\right)$ da matéria orgânica sedimentar.

\section{Atividades de laboratório}

No laboratório as amostras foram secas em estufa a $50^{\circ} \mathrm{C}$, sendo então descritas visualmente em relação à granulometria e tipos de grãos constituintes.

Dentre as atividades de laboratório foram realizadas as análises sedimentológicas: granulometria, de acordo com o método descrito em Suguio (1973), além das análises composicionais do sedimento: conteúdo em carbonato de cálcio e de matéria orgânica total determinados a partir da diferença, em peso seco, antes e após ataque com solução de $\mathrm{HCl}$ a $10 \%$ e de $\mathrm{H}_{2} \mathrm{O}_{2}$ a $10 \%$, respectivamente (INGRAM, 1971 apud SUGUIO, 1973; MULLER, 1967 apud SUGUIO, 1973).

Após um tratamento preliminar da amostra para a eliminação do $\mathrm{CaCO}_{3}$ existente, conforme descrito em Hedges e Stern (1984), a composição isotópica de carbono e nitrogênio foi determinada pela combustão automática da amostra em um analisador elementar Carlo Erba (CHN-1110), acoplado ao espectrômetro de massa Finnigan Delta Plus do Laboratório de Ecologia Isotópica do CENA-ESALQ-USP (Piracicaba, SP). Estes dados, expressos em \%, são obtidos em conjunto com os valores das razões isotópicas de carbono $\left(\delta^{13} \mathrm{C}\right)$ e nitrogênio $\left(\delta^{15} \mathrm{~N}\right)$. As amostras foram queimadas em meio oxidante, e os gases produzidos separados por cromatografia gasosa, purificados e carreados por um fluxo contínuo de Hélio. Os valores das razões isotópicas de carbono $\left(\delta^{13} \mathrm{C}\right)$ e nitrogênio $\left(\delta^{15} \mathrm{~N}\right)$ (em partes por mil) são referidos, respectivamente, ao PDB (Pee Dee Belemnite) e ao Ar (ar atmosférico).

\section{Tratamento dos dados}

Após a obtenção dos resultados os dados sofreram tratamento segundo os parâmetros estatísticos de Folk e Ward (1957) e do diagrama triangular de Shepard (1954) através do programa Sysgran (3.1), que permitiu a obtenção do diâmetro médio, grau de seleção, assimetria e curtose da distribuição dos sedimentos, além dos teores de grânulos, areia, silte e argila.

Ainda foi elaborada uma tabela relacionando as características granulométricas e geoquímicas do sedimento permitindo avaliar as influências das variações entre os parâmetros estudados. Esses índices de correlação linear foram obtidos através do programa de software Excel for Windows (7.0). O mapa e as figuras foram elaborados através do programa Surfer for Windows (8.0).

\section{RESULTADOS}

Os resultados obtidos nas etapas de campo e análises de laboratório estão representados em tabelas e figuras. 
OLIVEIRA, T. S.; BARCELLOS, R. L. Caracterização sedimentológica e geoquímica do apicum do sistema estuarino do Rio Itapessoca, Goiana - Pernambuco.

A figura 1 ilustra a localização das estações de coleta no apicum do estuário do Rio Itapessoca.

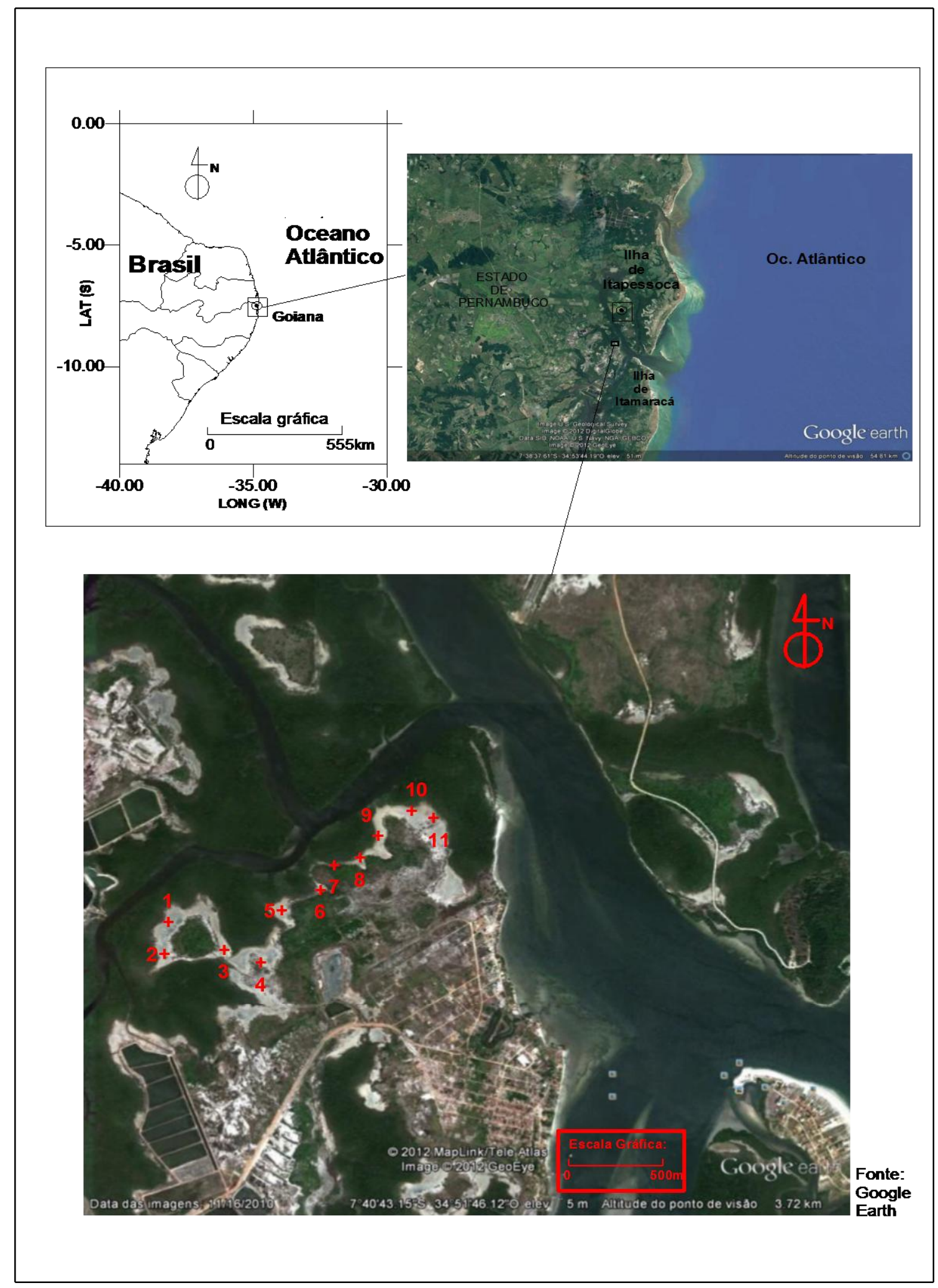

Figura 1 - Localização da área de estudo e das estações de coleta.

Nas tabelas 1 e 2 estão representadas as posições e os dados sedimentológicos (granulometria, classificação de Shepard (1954), parâmetros estatísticos de Folk e Ward 
OLIVEIRA, T. S.; BARCELLOS, R. L. Caracterização sedimentológica e geoquímica do apicum do sistema estuarino do Rio Itapessoca, Goiana - Pernambuco.

(1957), teores de carbonato biodetrítico, matéria orgânica total, C e $\mathrm{N}$ elementares, razões C/N e dos isótopos estáveis de carbono $\left(\delta^{13} \mathrm{C}\right)$ e nitrogênio $\left.\left(\delta^{15} \mathrm{~N}\right)\right)$ das estações de coleta.

Tabela 1 - Localização, classificação do diagrama triangular de Shepard (1954), parâmetros estatísticos de Folk e Ward (1957) e granulometria das amostras coletadas.

\begin{tabular}{|c|c|c|c|c|c|c|c|c|c|c|}
\hline \multirow{2}{*}{ Estação } & \multirow{2}{*}{$\begin{array}{l}\text { Latitude } \\
\qquad \mathbf{S}\end{array}$} & \multirow{2}{*}{$\begin{array}{c}\text { Longitude } \\
\text { W }\end{array}$} & \multirow{2}{*}{$\begin{array}{c}\text { Classifica } \\
\text { ção de } \\
\text { Shepard } \\
(\mathbf{1 9 5 4 )}\end{array}$} & \multicolumn{7}{|c|}{ Parâmetros de Folk e Ward (1957) } \\
\hline & & & & $\begin{array}{c}\text { Phi } \\
\text { médio }\end{array}$ & $\begin{array}{c}\text { G. } \\
\text { seleção }\end{array}$ & $\begin{array}{c}\text { \% } \\
\text { Grânulos } \\
\end{array}$ & $\begin{array}{c}\% \\
\text { Areia } \\
\end{array}$ & $\begin{array}{c}\% \\
\text { Silte } \\
\end{array}$ & $\begin{array}{c}\% \\
\text { Argila } \\
\end{array}$ & $\begin{array}{c}\% \\
\text { Lama } \\
\end{array}$ \\
\hline 1 & $07^{\circ} 40.807^{\prime}$ & $034^{\circ} 52.662^{\prime}$ & Areia & 2,55 & 1,23 & 0,35 & 92,44 & 6,48 & 0,73 & 7,21 \\
\hline 2 & $07^{\circ} 40.892^{\prime}$ & $034^{\circ} 52.694^{\prime}$ & Areia & 2,48 & 0,88 & 0,34 & 96,09 & 3,18 & 0,38 & 3,57 \\
\hline 3 & $07^{\circ} 40.901^{\prime}$ & $034^{\circ} 52.506^{\prime}$ & Areia & 1,92 & 1,36 & 0,30 & 95,87 & 3,24 & 0,59 & 3,83 \\
\hline 4 & $07^{\circ} 40.888^{\prime}$ & $034^{\circ} 52.368^{\prime}$ & Areia & 2,33 & 1,05 & 0,56 & 94,90 & 4,00 & 0,54 & 4,53 \\
\hline 5 & $07^{\circ} 40.771^{\prime}$ & $034^{\circ} 52.343^{\prime}$ & Areia & 2,50 & 0,94 & 0,38 & 97,12 & 2,18 & 0,31 & 2,50 \\
\hline 6 & $07^{\circ} 40.686^{\prime}$ & $034^{\circ} 52.225^{\prime}$ & Areia & 2,18 & 0,99 & 0,17 & 97,24 & 2,25 & 0,34 & 2,59 \\
\hline 7 & $07^{\circ} 40.613^{\prime}$ & $034^{\circ} 52.121^{\prime}$ & Areia & 2,38 & 1,22 & 0,31 & 92,90 & 5,64 & 1,15 & 6,79 \\
\hline 8 & $07^{\circ} 40.535^{\prime}$ & $034^{\circ} 52.036^{\prime}$ & Areia & 2,69 & 1,35 & 0,45 & 89,66 & 8,28 & 1,60 & 9,89 \\
\hline 9 & $07^{\circ} 40.468^{\prime}$ & $034^{\circ} 52.034^{\prime}$ & Areia & 2,62 & 1,42 & 0,80 & 90,62 & 7,12 & 1,46 & 8,58 \\
\hline 10 & $07^{\circ} 40.464^{\prime}$ & $034^{\circ} 51.941^{\prime}$ & Areia & 2,76 & 1,05 & 0,00 & 92,36 & 6,58 & 1,06 & 7,64 \\
\hline 11 & $07^{\circ} 40.523^{\prime}$ & $034^{\circ} 51.867^{\prime}$ & Areia & 2,27 & 1,21 & 0,21 & 92,60 & 6,04 & 1,15 & 7,19 \\
\hline
\end{tabular}

Tabela 2 - Localização, teores $\mathrm{C}$ e $\mathrm{N}$ elementares, razões $\mathrm{C} / \mathrm{N}$ e dos isótopos estáveis de carbono $\left(\delta^{13} \mathrm{C}\right)$ e nitrogênio $\left(\delta^{15} \mathrm{~N}\right)$, matéria orgânica total e teores de carbonato biodetrítico das amostras coletadas.

\begin{tabular}{|c|c|c|c|c|c|c|c|c|c|}
\hline Estação & $\begin{array}{l}\text { Latitude } \\
\mathbf{S}\end{array}$ & Longitude W & $\% \mathrm{C}$ & $\% N$ & $\mathrm{C} / \mathrm{N}$ & $\Delta^{13} \mathrm{C}$ & $\Delta^{15} \mathrm{~N}$ & $\begin{array}{l}\text { \%Matéria } \\
\text { Org. Total }\end{array}$ & $\% \mathrm{CaCO} 3$ \\
\hline 1 & $07^{\circ} 40.807^{\prime}$ & $034^{\circ} 52.662^{\prime}$ & 0,25 & 0,003 & 73,76 & $-22,43$ & 2,81 & 4,13 & 2,8 \\
\hline 2 & $07^{\circ} 40.892^{\prime}$ & $034^{\circ} 52.694^{\prime}$ & 0,29 & 0,003 & 83,87 & $-20,08$ & 2,95 & 2,97 & 3,8 \\
\hline 3 & $07^{\circ} 40.901^{\prime}$ & $034^{\circ} 52.506^{\prime}$ & 0,23 & 0,003 & 65,92 & $-20,90$ & 3,52 & 3,60 & 2,9 \\
\hline 4 & $07^{\circ} 40.888^{\prime}$ & $034^{\circ} 52.368^{\prime}$ & 0,19 & 0,003 & 55,89 & $-21,32$ & 3,29 & 4,67 & 4,3 \\
\hline 5 & $07^{\circ} 40.771^{\prime}$ & $034^{\circ} 52.343^{\prime}$ & 0,25 & 0,003 & 71,86 & $-21,22$ & 3,88 & 3,70 & 5,7 \\
\hline 6 & $07^{\circ} 40.686^{\prime}$ & $034^{\circ} 52.225^{\prime}$ & 0,19 & 0,022 & 8,48 & $-20,22$ & 3,42 & 2,43 & 1,7 \\
\hline 7 & $07^{\circ} 40.613^{\prime}$ & $034^{\circ} 52.121^{\prime}$ & 0,62 & 0,031 & 19,83 & $-22,52$ & 2,44 & 4,57 & 4,6 \\
\hline 8 & $07^{\circ} 40.535^{\prime}$ & $034^{\circ} 52.036^{\prime}$ & 0,38 & 0,003 & 111,42 & $-21,72$ & 3,44 & 3,93 & 7,7 \\
\hline 9 & $07^{\circ} 40.468^{\prime}$ & $034^{\circ} 52.034^{\prime}$ & 0,31 & 0,003 & 89,12 & $-19,31$ & 2,97 & 4,40 & 6,5 \\
\hline 10 & $07^{\circ} 40.464^{\prime}$ & $034^{\circ} 51.941^{\prime}$ & 0,27 & 0,003 & 78,08 & $-20,21$ & 3,62 & 5,40 & 7,5 \\
\hline 11 & $07^{\circ} 40.523^{\prime}$ & $034^{\circ} 51.867^{\prime}$ & 0,25 & 0,003 & 71,89 & $-20,00$ & 3,41 & 4,00 & 3,7 \\
\hline
\end{tabular}

Tabela 3 - Análise de correlação linear entre os parâmetros granulométricos e geoquímicos do sedimento.

\begin{tabular}{|c|c|c|c|c|c|c|c|c|}
\hline & $\% \mathrm{CaCO}_{3}$ & \% MO & $\%$ C & $\% \mathbf{N}$ & $\delta^{13} \mathrm{C}$ & $\delta^{15} \mathrm{~N}$ & $R z C / N$ & \% Lama \\
\hline$\% \mathrm{CaCO}_{3}$ & 1,00 & $x$ & $x$ & $x$ & $x$ & $x$ & $x$ & $x$ \\
\hline \% MO & 0,61 & 1,00 & $x$ & $x$ & $x$ & $x$ & $x$ & $x$ \\
\hline$\%$ C & 0,31 & 0,29 & 1,00 & $x$ & $x$ & $x$ & $x$ & $x$ \\
\hline$\% \mathrm{~N}$ & $-0,30$ & $-0,17$ & 0,61 & 1,00 & $x$ & $x$ & $x$ & $x$ \\
\hline$\delta^{13} \mathrm{C}$ & 0,08 & $-0,18$ & $-0,47$ & $-0,32$ & 1,00 & $x$ & $x$ & $x$ \\
\hline$\delta^{15} \mathrm{~N}$ & 0,22 & $-0,10$ & $-0,63$ & $-0,48$ & 0,33 & 1,00 & $x$ & $x$ \\
\hline Razão C/N & 0,62 & 0,25 & $-0,14$ & $-0,84$ & 0,17 & 0,24 & 1,00 & $x$ \\
\hline$\%$ Lama & 0,61 & 0,60 & 0,43 & $-0,15$ & $-0,10$ & $-0,29$ & 0,51 & 1,00 \\
\hline
\end{tabular}


OLIVEIRA, T. S.; BARCELLOS, R. L. Caracterização sedimentológica e geoquímica do apicum do sistema estuarino do Rio Itapessoca, Goiana - Pernambuco.

De acordo com o diagrama triangular de Shepard (1954), as amostras coletadas no apicum do estuário do Rio Itapessoca, são areias. E, segundo os parâmetros estatísticos de Folk e Ward (1957), apresentam predomínio de diâmetro médio areia fina (2,00 a 3,00 $\varphi$ ) (91\% das amostras) (Fig. 2), com preponderância de sedimentos moderadamente a pobremente selecionados $(0,88$ a 1,41) (Fig. 3) e com baixos conteúdos de lama $(2,50$ a 9,89) (Fig. 4).

A correlação apresentada entre os teores de lama e matéria orgânica total $\left(r^{2}=0,60\right)$ (Tab. 3 ), indicou que a acumulação de matéria orgânica é fortemente dependente da quantidade de argila depositada, devido ao processo de adsorção. O conteúdo orgânico, desta forma, é diretamente correlacionado com a porcentagem de argila no sedimento (Tab. 2). De forma análoga, a lama e o carbonato de cálcio apresentaram correlação diretamente proporcional $\left(r^{2}=0,61\right)$ evidenciando que tanto as lamas quanto o carbonato biodetrítico são diretamente influenciados pelas águas estuarinas. A característica da matéria orgânica de origem mista tendendo a marinha, para o conjunto de amostras do apicum, demonstra que o aporte estuarino é fator determinante para a presença de lamas, carbonatos e matéria orgânica nos sedimentos da área.

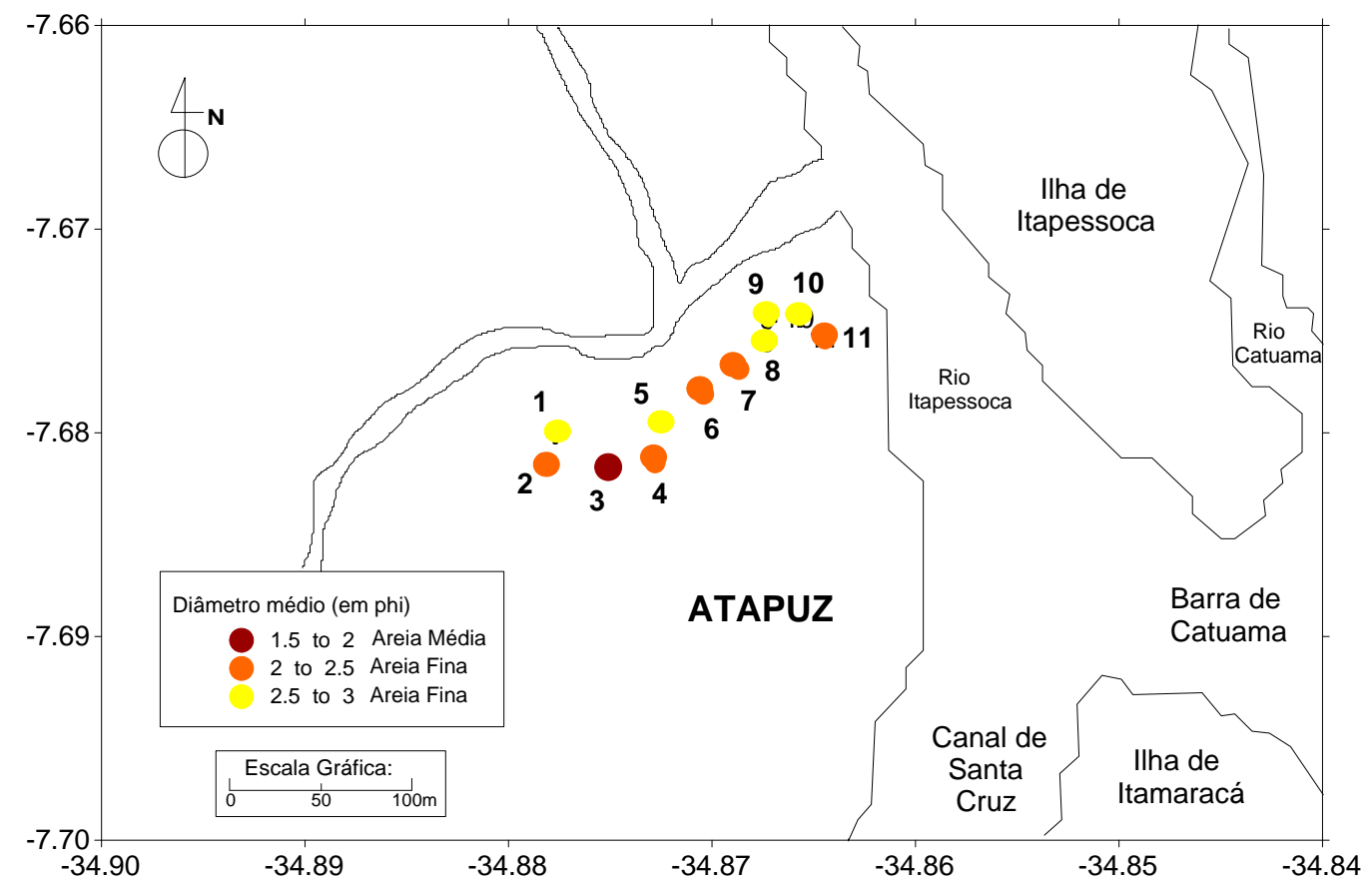

Figura 2 - Diâmetro médio dos sedimentos (em phi) - parâmetros de Folk e Ward, 1957.

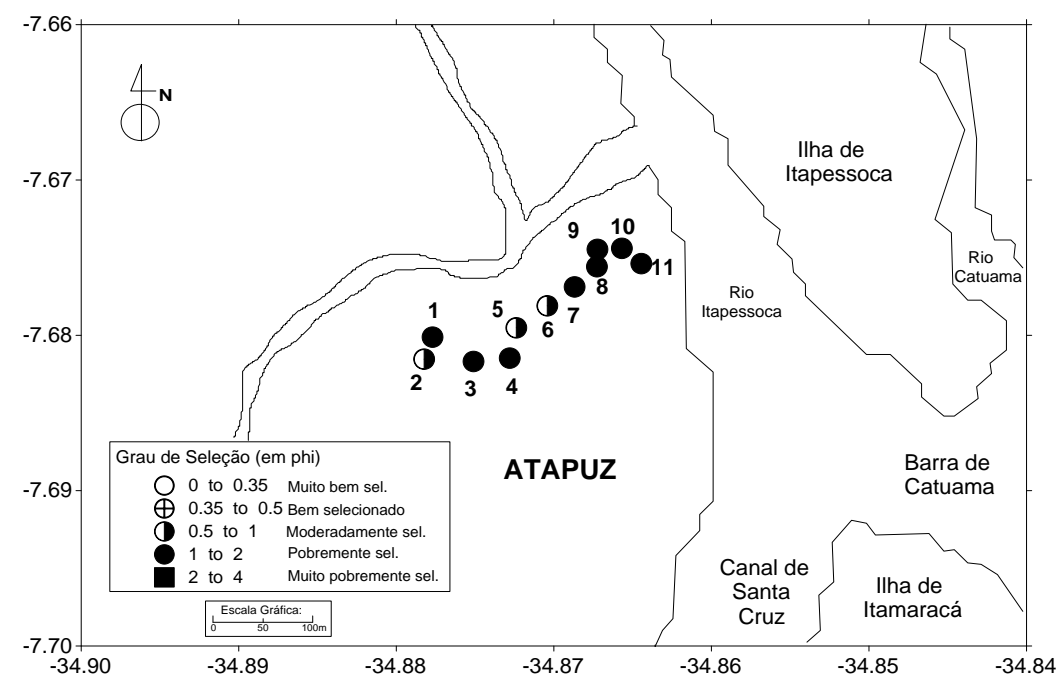

Figura 3 - Grau de seleção dos sedimentos (em phi) - parâmetros de Folk e Ward, 1957. 
OLIVEIRA, T. S.; BARCELLOS, R. L. Caracterização sedimentológica e geoquímica do apicum do sistema estuarino do Rio Itapessoca, Goiana - Pernambuco.

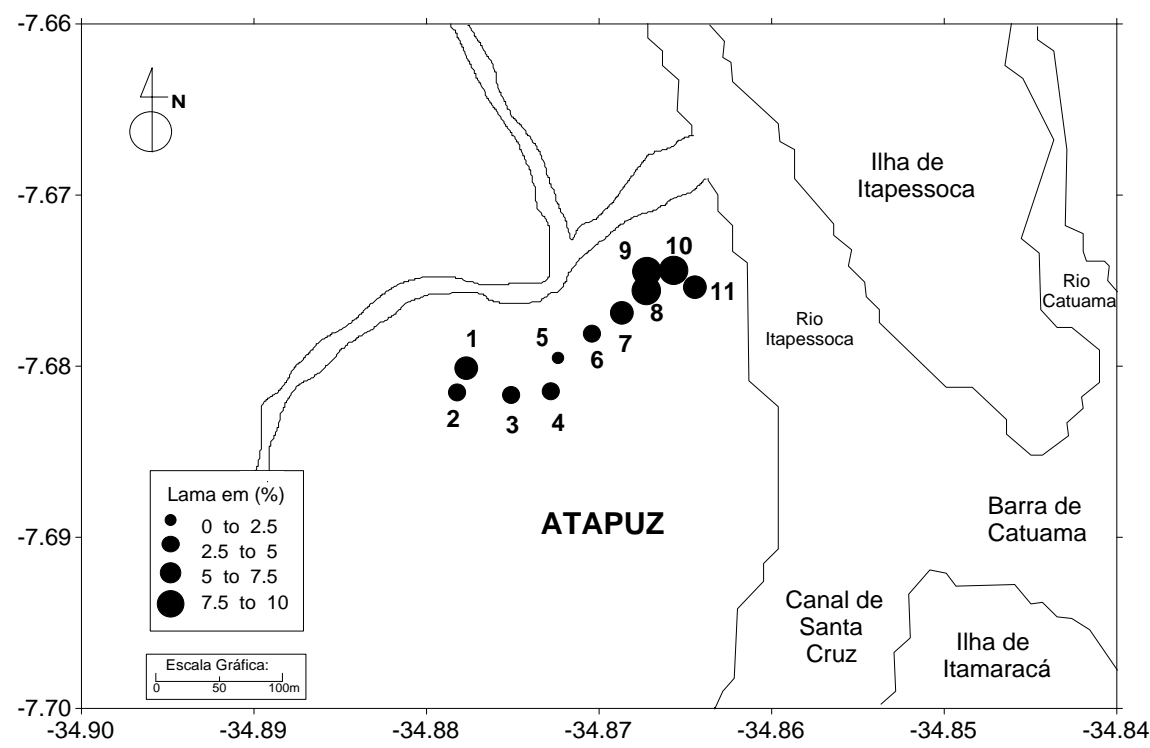

Figura 4 - Teores de lama em (\%) nos sedimentos.

Os teores de carbono orgânico observados variaram de 0,19 a 0,62\% (Fig. 5).

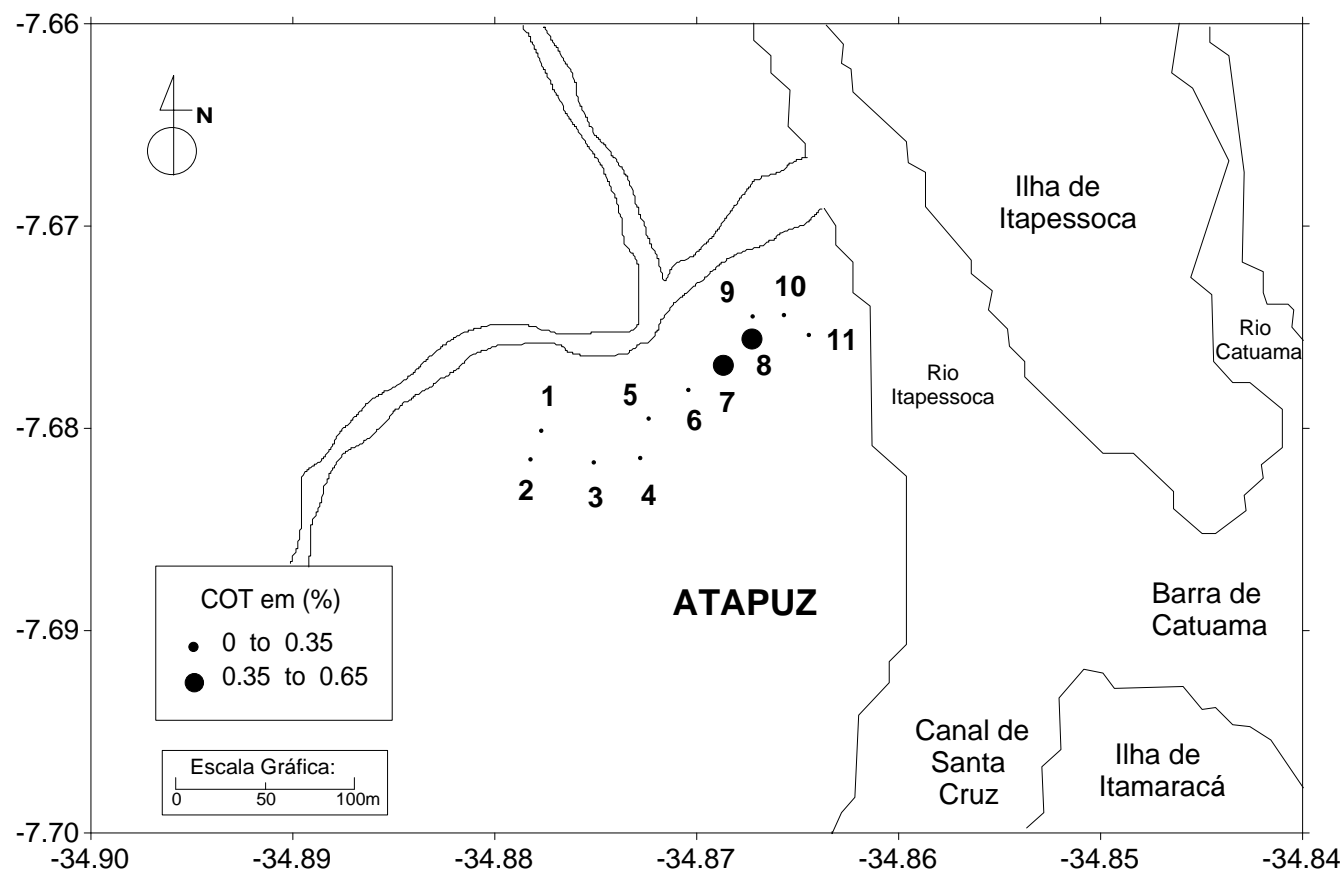

Figura 5 - Conteúdos de carbono orgânico (em \%) dos sedimentos coletados. 
OLIVEIRA, T. S.; BARCELLOS, R. L. Caracterização sedimentológica e geoquímica do apicum do sistema estuarino do Rio Itapessoca, Goiana - Pernambuco.

Os teores de nitrogênio total observados variaram de 0,003 a 0,031\% (Fig. 6).

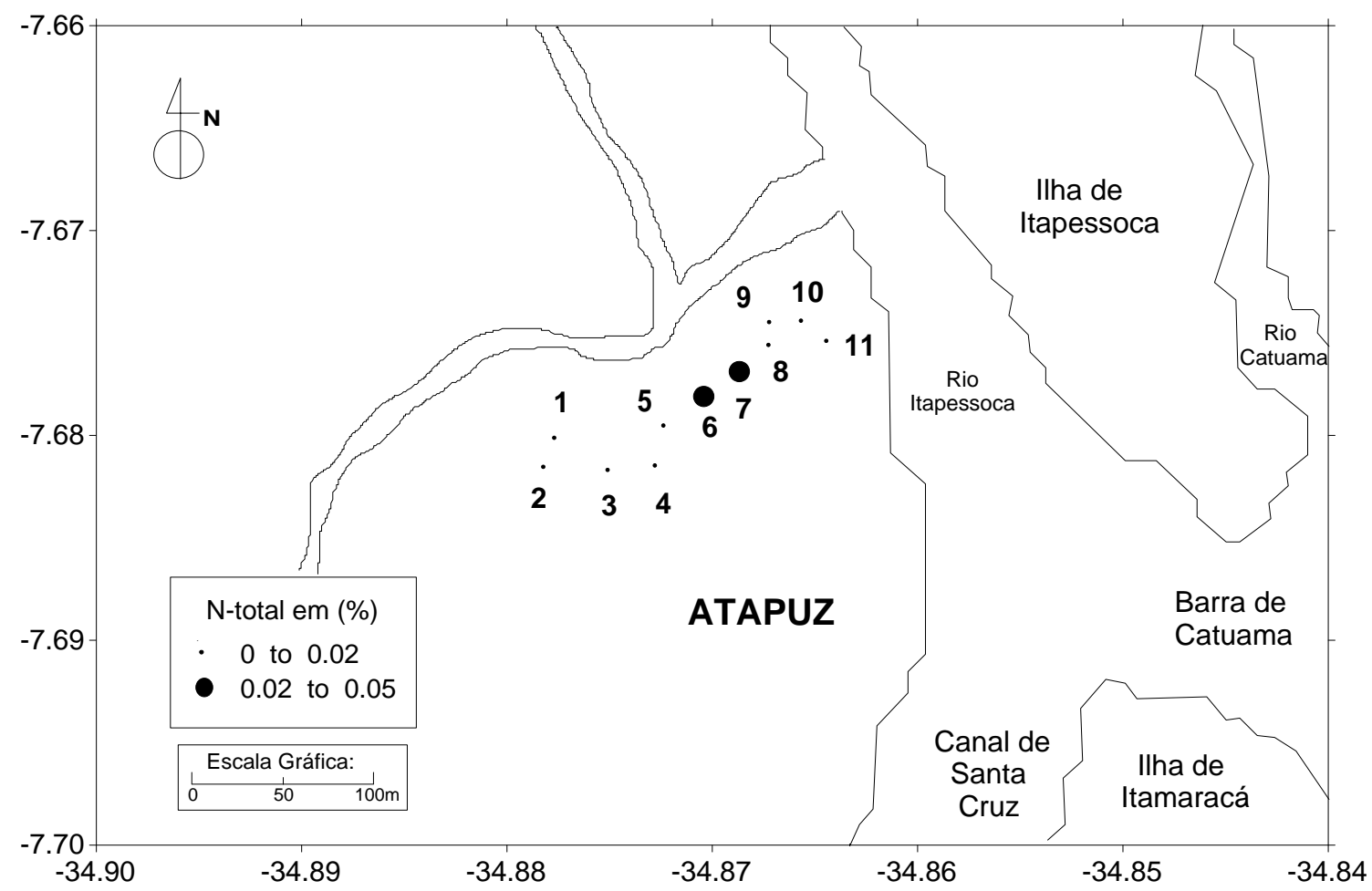

Figura 6 - Conteúdos de nitrogênio total em (\%) dos sedimentos coletados.

Os valores da razão C/N variaram de 8,48 a 111,42 (Fig. 7), apresentando os menores valores nas estações 6 e 7 .

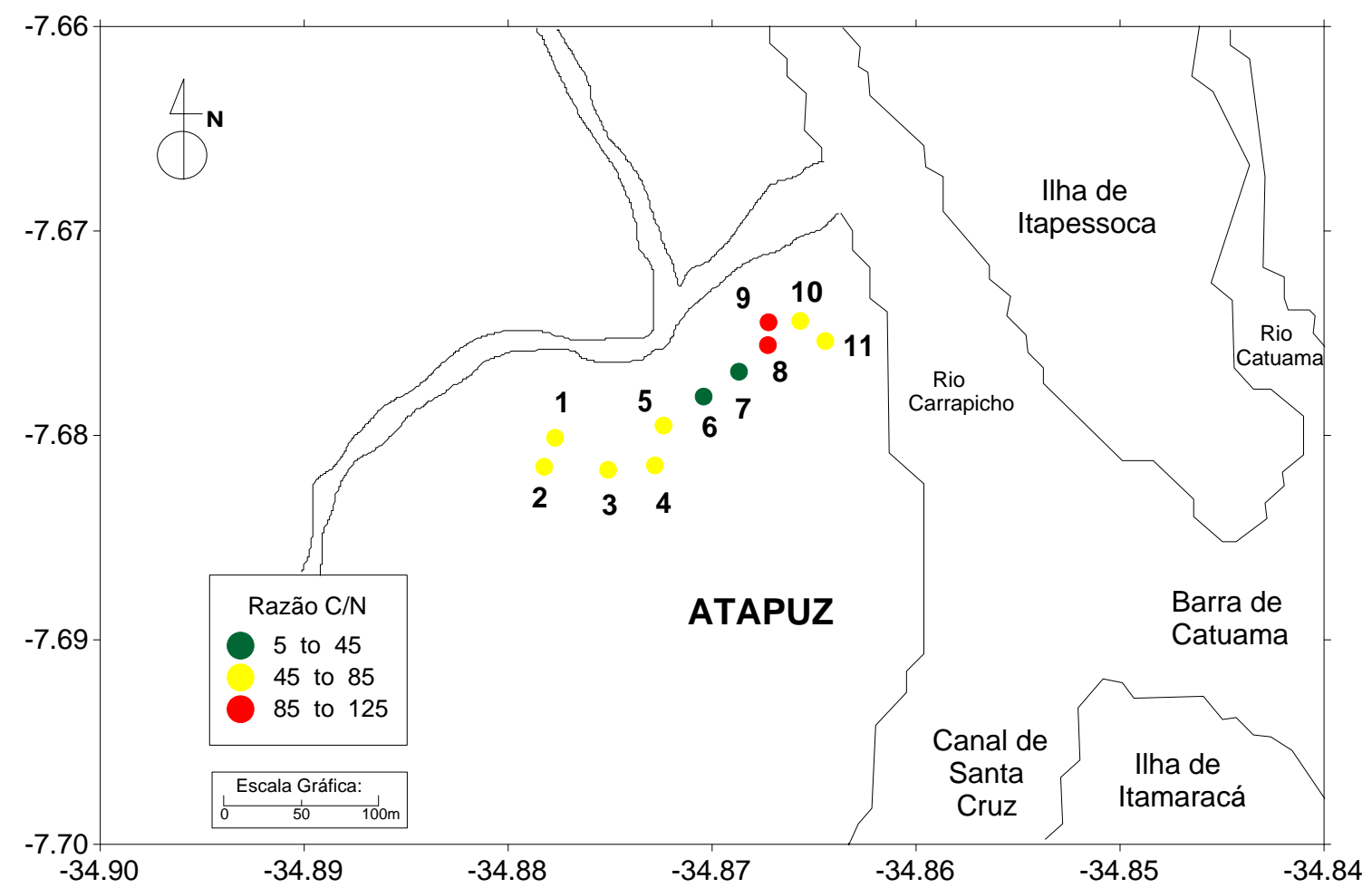

Figura 7 - Valores da razão C/N nos sedimentos. 
OLIVEIRA, T. S.; BARCELLOS, R. L. Caracterização sedimentológica e geoquímica do apicum do sistema estuarino do Rio Itapessoca, Goiana - Pernambuco. (Fig. 8)

Os conteúdos da razão isotópica $\delta^{13} \mathrm{C}$ observados variaram de $-22,52$ a $-19,31 \%$ PDB

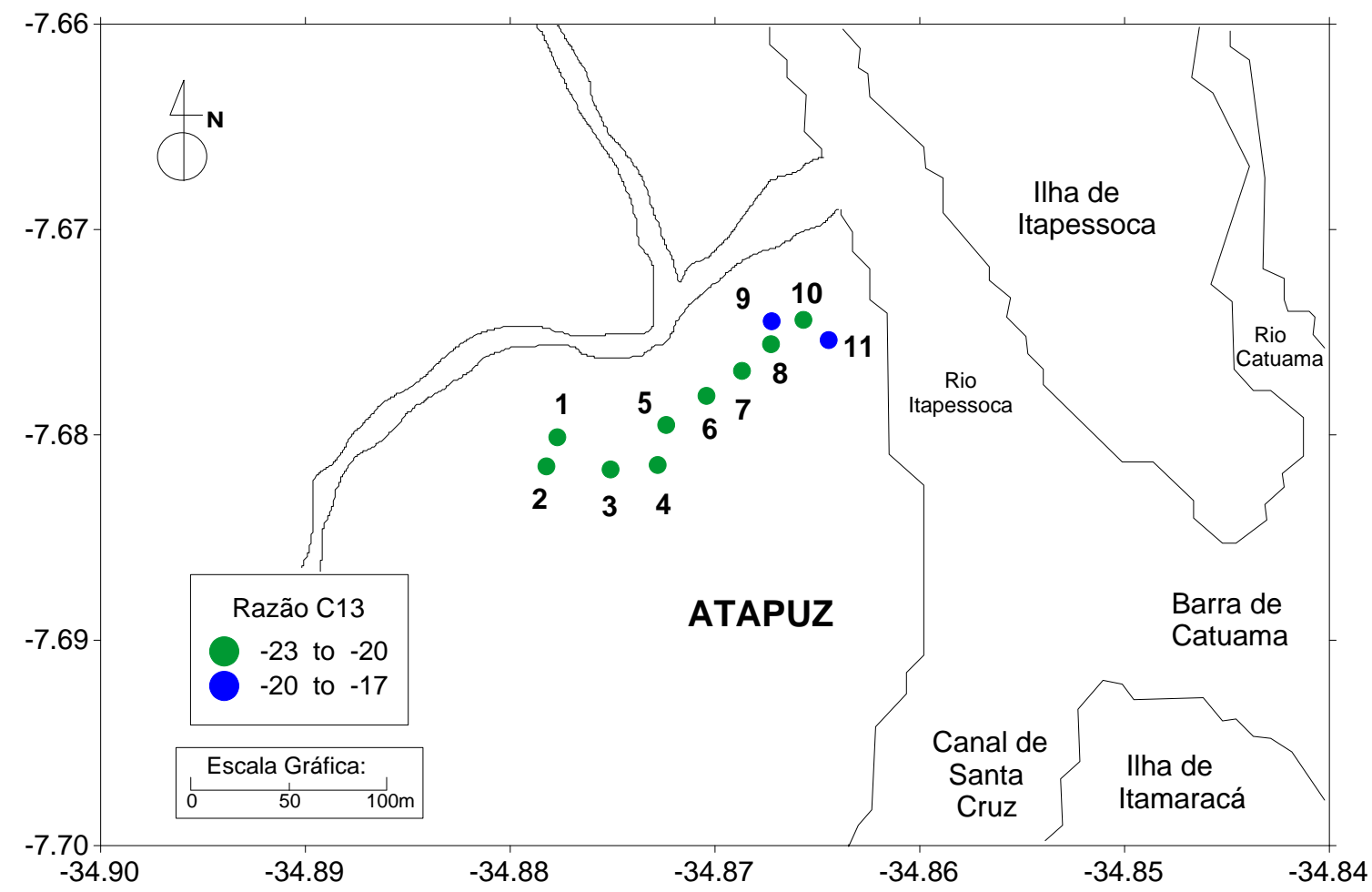

Figura 8 - Razão isotópica $\delta^{13} \mathrm{C}$ dos sedimentos coletados.

Os conteúdos da razão isotópica $\delta^{15} \mathrm{~N}$ observados variaram de 2,44 a 3,88\% Ar (Fig. 9).

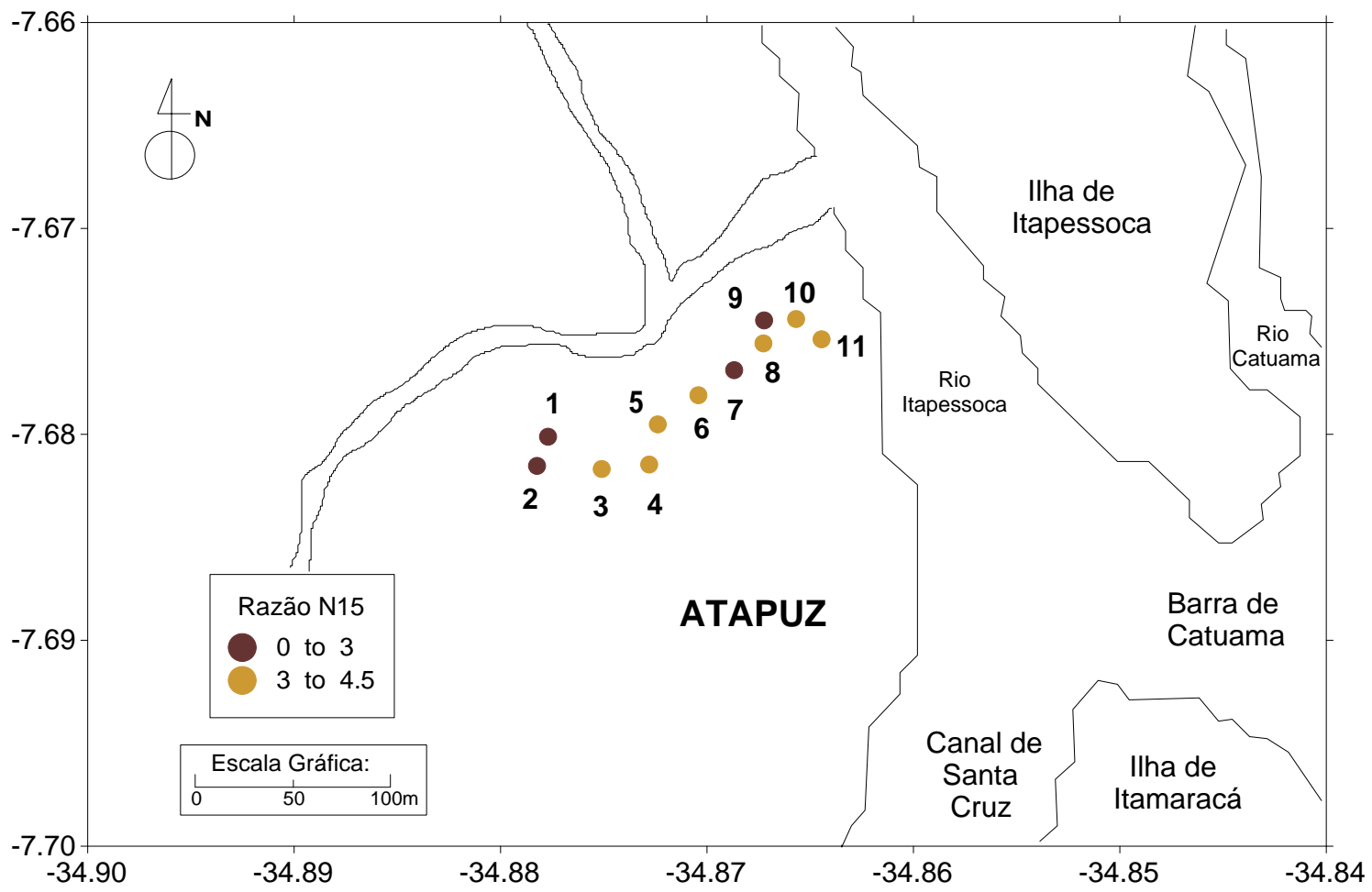

Figura 9 - Razão isotópica $\delta^{15} \mathrm{~N}$ dos sedimentos coletados. 
OLIVEIRA, T. S.; BARCELLOS, R. L. Caracterização sedimentológica e geoquímica do apicum do sistema estuarino do Rio Itapessoca, Goiana - Pernambuco.

A matéria orgânica total variou de 2,43 a 5,4\% (Fig. 10), apresentando maior teor na estação 10.

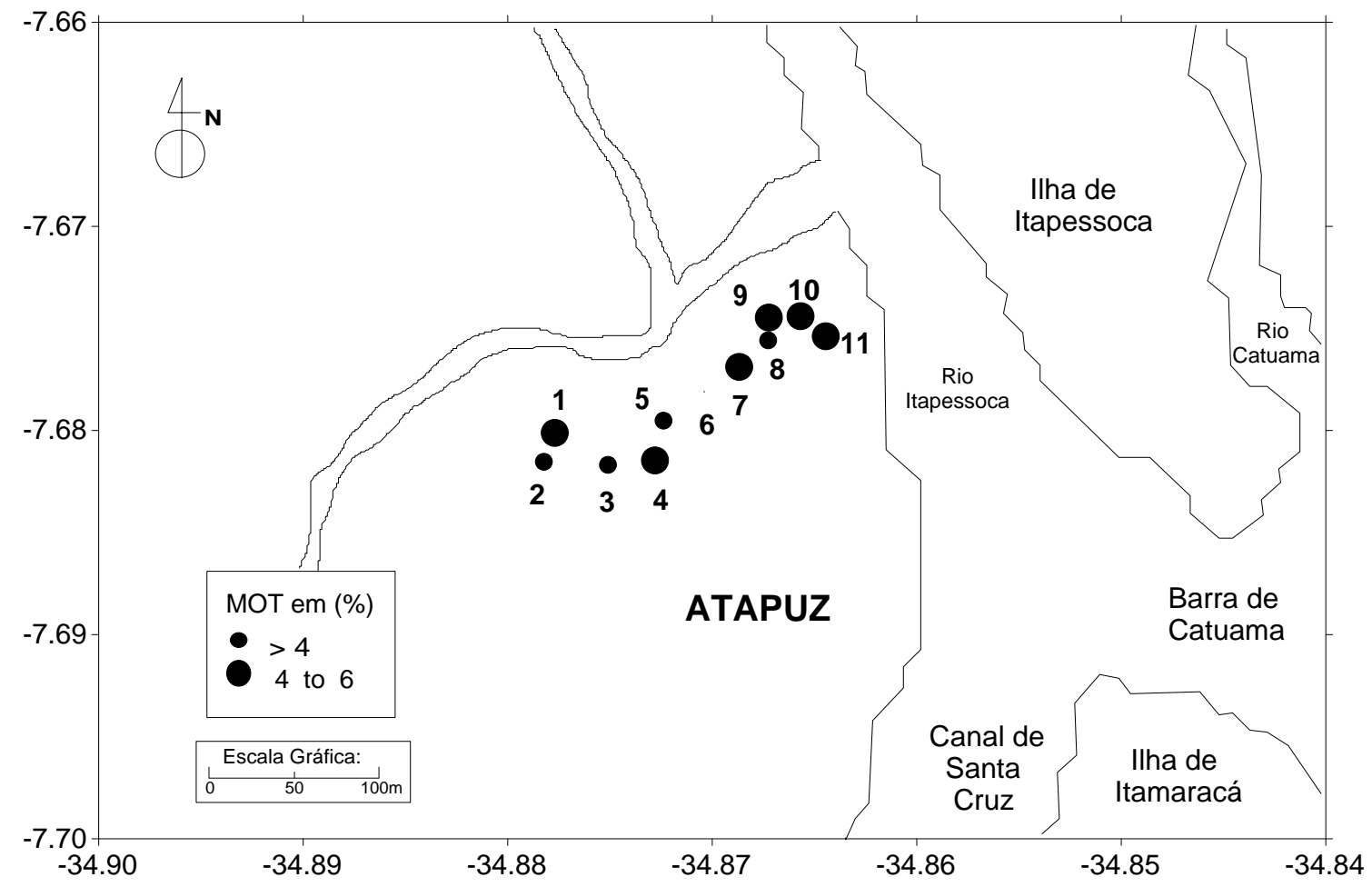

Figura 10 - Conteúdos de matéria orgânica total (em \%) dos sedimentos coletados.

Os valores do carbonato biodetrítico foram extremamente baixos, variando de 1,7 a 7,7 (Fig. 11), estando em maior quantidade na estação 8.

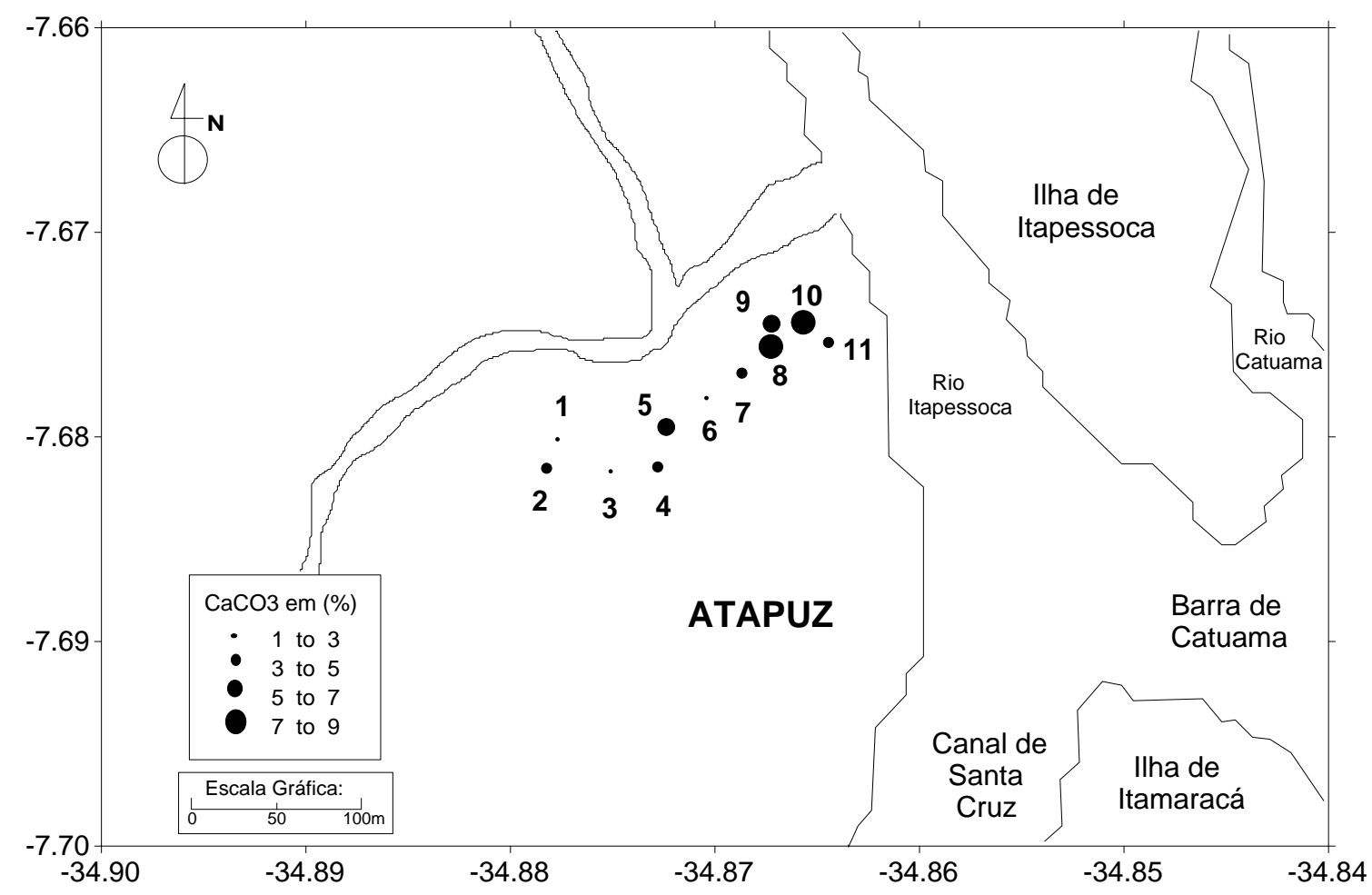

Figura 11 - Teores de carbonato biodetrítico em (\%) dos sedimentos. 
OLIVEIRA, T. S.; BARCELLOS, R. L. Caracterização sedimentológica e geoquímica do apicum do sistema estuarino do Rio Itapessoca, Goiana - Pernambuco.

Com relação à origem da matéria orgânica, expressa através dos valores obtidos para a razão $\mathrm{C} / \mathrm{N}$ (Tab. 2), pode-se afirmar que apenas as estações $6(8,48)$ e $7(19,83)$ apresentaram resultados interpretáveis, a primeira indicando matéria orgânica de origem mista tendendo a marinha, reforçada pelo valor do $\delta^{13} \mathrm{C}(-20,22 \%$ PDB $)$; e a segunda, matéria orgânica de origem continental. Resultado este, corroborado pela correlação moderada entre os teores de carbono orgânico e nitrogênio: $r^{2}=0,61$ (Tab. 3) apontando fontes diferentes de matéria orgânica. Os valores obtidos nas demais amostras ( $>50$ ), não refletem sua origem.

Barcellos (2000) e Barcellos; Furtado (2006) observaram que amostras que apresentam essa tendência localizam-se, principalmente, em áreas que possuem baixos teores orgânicos em sedimentos eminentemente arenosos, podendo estes valores serem influenciados por estes baixos teores. Bader (1955) notou uma relação direta entre quantidade de matéria orgânica muito baixa $(<0,25 \% \mathrm{C}$ e $<0,01 \% \mathrm{~N})$ e altos valores de $\mathrm{C} / \mathrm{N}(>30)$.

\section{DISCUSSÃO}

Os sedimentos analisados foram homogêneos para todos os parâmetros, pois conforme já descrito nos resultados são areias finas litoclásticas, moderadamente a pobremente selecionadas com baixos conteúdos de lamas, carbonatos e matéria orgânica.

Independentemente desta homogeneidade observam-se diferenças sutis entre as amostras localizadas a leste, próximas ao canal do Rio Itapessoca (estações 7 a 11), com maiores teores de carbonatos, lamas e consequentemente mais matéria orgânica e as amostras localizadas na porção mais continental (estações 1 a 5) compostas de sedimentos arenosos estéreis. A estação 6 possui características de ambos os grupos, estaria representando uma zona de transição na área de estudo.

Sedimentos com características similares, apresentando propriedades essencialmente arenosas, também foram observados em estudos anteriores realizados em amostras de apicum (SCHAEFFER-NOVELLI, 1999; HADLICH et al., 2008 e UCHA et al., 2008). Tal resultado reflete um ambiente com baixo hidrodinamismo, uma vez que os apicuns localizam-se em regiões altas relativamente ao manguezal e são alcançados apenas por marés de sizígia, imprimindo um aporte de sedimentos pouco constante. O fluxo esporádico das marés no apicum remove grãos mais finos (lamas), deixando apenas grãos mais grosseiros (areias).

Susilo (2005), também fez observações sobre o tamanho da partícula do sedimento em um apicum ser significativamente mais grosseiro em comparação com os encontrados em manguezais. Esse padrão no resultado com predomínio de sedimento arenoso corrobora com a definição dada por Nascimento (1993) à feição apicum, "salgado, areal, zona de solo geralmente arenoso".

Porém, sedimentos lamosos foram encontrados em maior quantidade no apicum da Baía de Sepetiba, por Pellegrini (2000), em comparação com os valores de fração mais grosseira (areia).

No que diz respeito aos valores de carbono orgânico e nitrogênio total, Hadlich et al. (2010) em suas análises com os sedimentos de apicum na Baía de Todos os Santos, também encontraram baixos teores destes dois parâmetros, onde tais valores aumentam em direção ao manguezal. De fato, no presente estudo, em baixos níveis, também foram encontrados, teores um pouco maiores de carbono orgânico e nitrogênio total nas amostras coletadas mais próximas à franja do mangue de maior dimensão associado ao canal de drenagem principal do rio Itapessoca (estações 7 a 11).

A matéria orgânica sedimentar, de acordo com os valores observados para a razão isotópica $\delta^{13} \mathrm{C}$, indicou ser predominantemente de origem marinha em especial nas amostras próximas ao canal do Rio Itapessoca com teores mais enriquecidos ( $>-20 \%$ oPDB) (CHESTER; RILEY, 1978; STEIN, 1991; MEYERS, 1997; LAMB et al., 2006). A razão isotópica $\delta^{15} \mathrm{~N}$ apresentou, por sua vez, um comportamento particular para a área, indicativo de matéria orgânica de origem mista tendendo a continental. Fato que pode estar relacionado à sobreposição dos conteúdos isotópicos das fontes de matéria orgânica terrígenas. De acordo 
OLIVEIRA, T. S.; BARCELLOS, R. L. Caracterização sedimentológica e geoquímica do apicum do sistema estuarino do Rio Itapessoca, Goiana - Pernambuco.

com Kaplan (1975) apud Chester e Riley, 1978) as plantas superiores $\left(C_{3}\right)$ são caracterizadas por valores de $\delta^{15} \mathrm{~N}$ que variam de -4 a $8 \% \mathrm{Ar}$ (em relação ao padrão $\mathrm{Ar}$ ), enquanto que 0 fitoplâncton e as algas marinhas apresentam valores maiores e que variam de 2 a $8 \%$ Ar e 4 a $11 \% \mathrm{Ar}$, respectivamente.

Os percentuais de matéria orgânica total e carbonato biodetrítico apresentaram baixa concentração nas amostras coletadas. Porém, maiores teores foram observados nas amostras 7 a 11 devido à proximidade do rio Itapessoca. Resultados semelhantes foram encontrados nos poucos estudos envolvendo tais parâmetros por Pellegrini (2000), Ucha et al. (2008) e Hadlich et al. (2008 e 2010), que fizeram a mesma observação.

\section{CONCLUSÃO}

O apicum estudado no Estuário do Rio Itapessoca é um ambiente predominantemente arenoso que apresenta uma granulometria que reflete as condições ambientais da área. Os sedimentos litoclásticos moderadamente a pobremente selecionados com teores orgânicos muito baixos indicam, por sua vez, que a feição sofre pouca influência dos aportes de sedimento e matéria orgânica marinha e continental, porém predominando ainda a influência das marés como fonte de material. Tais características observadas na área de estudo se assemelham, de acordo com a literatura, aos dados de trabalhos em outros apicuns do Brasil e do mundo.

\section{REFERÊNCIAS}

BADER, R. G. Carbon and Nitrogen Relations in Surface Sediments. Geochimica et Cosmochimica Acta, v. 7, p. 205-211, 1955.

BARCELLOS, R. L. Processo Sedimentar atual e a Distribuição da Matéria Orgânica Sedimentar (C, N e S) de São Sebastião (SP) e Plataforma Continental adjacente. São Paulo, 2000. 187 f. Dissertação (Mestrado em Oceanografia Química e Geológica) - Instituto Oceanográfico, Universidade de São Paulo.

BARCELLOS, R. L. Distribuição da material organic sedimentary e processo sedimentar atual no sistema Estuarino Lagunar de Cananéia-Iguape, SP. São Paulo, 2005. 187 f. Tese (Doutorado em Oceanografia Geológica) - Instituto Oceanográfico, Universidade de São Paulo.

BARCELLOS, R. L.; CAMARGO, P. B.; Brizzotti, M. M.; FURTADO, V. V. Seasonal stable carbon isotope variations in sediments of Cananéia-Iguape Lagoonal Estuarine system, São Paulo State, SE Brazil. Materials and Geoenvironment, v. 1, p. 188-188, 2005.

BARCELLOS, R. L.; FURTADO, V. V. Organic Matter Contents and Modern Sedimentation at São Sebastião Channel, São Paulo State, South-Eastern Brazil. Journal of Coastal Research, Brasil, v. 39, p. 1073-1077, 2006.

BARCELLOS, R. L.; CAMARGO, P. B.; GALVAO, A.; WEBER, R. R. Sedimentary organic matter in cores of Cananéia-Iguape lagoonal-estuarine system, São Paulo State, Brazil. Journal of Coastal Research, v. 56, p. 1335-1339, 2009.

BARCELLOS, R. L.; XAVIER, D. A.; CAMARGO, P. B.; Feitosa. F. A. N.; MACEDO, S. J.

Características Sedimentológicas e Geoquímicas do Complexo Estuarino do Pina e Plataforma Continental Adjacente, Estado de Pernambuco, Brasil. In: CONGRESSO LATINO-AMERICANO DE CIÊNCIAS DO MAR, XIV, 2011, Balneário Camboriú. Anais... Balneário Camboriú: XIV COLACMAR, 2011. CD.

BARLETTA, M.; COSTA, M. F. Living and nonliving resources exploitation in a tropical semi-arid estuary. J. Coast. Res., v. 56, p. 371-375, 2009.

BOGGS, S. Principles of Sedimentology and Stratigraphy. New Jersey: Prentice Hall, 1995. 765p.

CHESTER, R.; RILEY J. P. Chemical Oceanography. London: Academic Press Inc. Ltd.. v. 07, 1978. 508p. 
OLIVEIRA, T. S.; BARCELLOS, R. L. Caracterização sedimentológica e geoquímica do apicum do sistema estuarino do Rio Itapessoca, Goiana - Pernambuco.

CINTRÓN, G.; GOENAGA, C.; LUGO; A. E. Observaciones sobre el desarrollo del manglar en costas áridas. In: Memorias del seminario sobre el estudio científico e impacto humano en el ecosistema de manglares. UNESCO, 1980. p. 18-32.

COELHO-JR, C. Gradiente de inundação pelas marés e a drenagem terrestre sobre o comportamento da salinidade intersticial de bosque de mangue de Cananéia, São Paulo, Brasil.

Revista de Gestão Costeira Integrada. Número Especial 2 - Manguezais do Brasil. No prelo.

COELHO - JR, C.; SCHAEFFER-NOVELLI, Y. Considerações teóricas e práticas sobre o impacto da carcinocultura nos ecossistemas costeiros brasileiros, com ênfase no ecossistema manguezal. Recife: Mangrove, 2000. 8 p.

Disponível em, http://www.redmanglar.org/ebol/docs/Impactosmanguezal.doc. Acessado em 13 de jun. 2010.

CONDEPE (Agência estadual de pesquisa e planejamento de Pernambuco). Perfil fisiográfico das bacias de Pernambuco. Recife, 1980. 257p.

CPRH (COMPANHIA PERNAMBUCANA DO MEIO AMBIENTE E RECURSOS HÍDRICOS).

Diagnóstico Socioambiental do Litoral Norte de Pernambuco. Recife (PE): CPRH/GERCO, 2003. 211p.

CPRM (Serviço Geológico do Brasil). Projeto cadastro de fontes de abastecimento por água subterrânea: diagnóstico do município de Goiana. Pernambuco, 2005. 21p.

CREPANI, E.; MEDEIROS, J. S. de. Carcinicultura em apicum no litoral do Piauí: uma análise com sensoriamento remoto e geoprocessamento. In: SIMPÓSIO BRASILEIRO DE

SENSORIAMENTO REMOTO, 11, 2003, Belo Horizonte. Anais... São José dos Campos: INPE, 2003. p. 1541-1548.

FREITAS, R. C. ; BARCELLOS, R. L.; PISETTA, M.; RODRIGUES, M.; FURTADO, V. V. O canal do Valo Grande e o assoreamento no sistema estuarino-lagunar de Cananéia-Iguape, Estado de São Paulo Brasil. In: BRAGA, E. de S. (Org.). Oceanografia e Mudanças Globais. 1ed. São Paulo: Editora do IOUSP, 2008, v. único, p. 771-783.

FOLK, R. L.; WARD, W. C. Brazos River Bar: A significance of Grain Size Parameters. Journal of Sedimentary Petrology. v. 27, n. 1, p. 3-26, 1957.

HADLICH, G. M.; UCHA, J. M.; CELINO, J. J. Apicuns na Baía de Todos os Santos: distribuição espacial, descrição e caracterização física e química. In: Queiroz, A. F. de S.; Celino, J. J. (Org.). Avaliação de ambientes na Baía de Todos os Santos: aspectos geoquímicos, geofísicos e biológicos. Salvador: UFBA, 2008. p. 59-72.

HADLICH, G. M.; UCHA, J. M. Apicuns: Aspectos Gerais, Evolução Recente e Mudanças Climáticas Globais. Revista Brasileira de Geomorfologia. v. 10, n. 2, 2009.

HADLICH, G. M.; CELINO, J. J.; UCHA, J. M. Diferenciação físico-química entre apicuns, manguezais e encostas na Baía de Todos os Santos, nordeste do Brasil. Geociências, São Paulo, v. 29, p. 633-641, 2010. Disponível em, http://drifte.rc.unesp.br/revistageociencias/29_4/Art\%2016_Hadlich.pdf. Acessado em 12 de dez. 2011.

HANSEN, K. Sediments from Danish Lakes. Journal of Sedimentary Petrology, vol. 29, n. 1, p. 38-46, 1959.

HEDGES, J. I.; STERN J. H. Carbon and nitrogen determinations in carbonate containing solids. Limnol. Oceanogr, v. 29, p. 45-57, 1984.

JESUS, R. S. Apicuns: evolução recente e importância social em Madre de Deus e em Saubara, Bahia. Salvador, 2008. Monografia (Graduação em Geografia) - Instituto de Geociências.

Universidade Federal da Bahia.

JESUS, R. S.; HADLICH, G. M. Análise multitemporal de apicuns em Madre de Deus e Saubara, Bahia. In: SIMPÓSIO BRASILEIRO DE SENSORIAMENTO REMOTO, XIV, 2009, Brasil.

Anais...Natal: 2009, p. 25-30. 
OLIVEIRA, T. S.; BARCELLOS, R. L. Caracterização sedimentológica e geoquímica do apicum do sistema estuarino do Rio Itapessoca, Goiana - Pernambuco.

LAMB, A. L.; GRAHAM, P. W.; LENG, M. J. A review of coastal paleoclimate and relative sealevel reconstructions using $\delta^{13} \mathrm{C}$ and $\mathrm{C} / \mathrm{N}$ ratios in organic matter. Earth-Science Reviews, $v$. 75, p. 29-57, 2006.

LIMA, M. R. B. L de M. A. de. Natureza e Origem da Matéria Orgânica Depositada sobre os Sedimentos Superficiais ao longo da Plataforma Continental entre as Cidades do Rio de Janeiro (RJ) e São Francisco do Sul (SC). São Paulo, 2000. 115 f. Dissertação (Mestrado em Oceanografia Geológica e Química) - Instituto Oceanográfico. Universidade de São Paulo.

MACIEL, N. C. Alguns aspectos da ecologia do manguezal. In: CPRH, 1991. Alternativas de uso e proteção dos manguezais do Nordeste. Recife, Companhia Pernambucana de Controle da Poluição Ambiental e de Administração dos Recursos Hídricos. Série Publicações Técnicas, n. 003, p. 9-37. 1991.

MAHIQUES, M. M. de. Dinâmica Sedimentar atual nas Enseadas da Região de Ubatuba, Estado de São Paulo. Bolm Inst. oceanogr., v.43, n²: p. 111-122, 1995.

MARCONDES, A. C. J. Sedimentologia e morfologia da Bacia do Pina, Recife-PE. Recife, 2009. 89 f. Dissertação (Mestrado em Geociências) - Departamento de Geologia. Universidade Federal de Pernambuco.

MASSELINK, G.; HUGHES, M. G. Introduction to Coastal Processes e Geomorphology. London: Hodder Arnold, 2003. 354 p.

MEYERS, P. A. Organic Geochemical Proxies of Paleoceanography, Paleolminologic and Paleoclimatic Processes. Organic Geochemistry, v. 27, p. 213-250, 1997.

NASCIMENTO, S. Estudo da importância do "apicum" para o ecossistema de manguezal. Relatório Técnico Preliminar. Sergipe, Governo do Estado do Sergipe, 1993. 27 p.

NASCIMENTO FILHO, G. A. Desenvolvimento estrutural e padrão de zonação dos bosques de mangue do rio Ariquindá, Baía de Tamandaré, Pernambuco. Recife, 2007. 82 f. Dissertação (Mestrado em Oceanografia) - Departamento de Oceanografia. Universidade Federal de Pernambuco.

PELLEGRINI, J. A. C. Caracterização da planície hipersalina (apicum) associada a um bosque de mangue em Guaratiba, Baía de Sepetiba, Rio de Janeiro- RJ. São Paulo, 2000. 114 f. Dissertação (Mestrado em Oceanografia Biológica) - Instituto Oceanográfico, Universidade de São Paulo.

PETTIJOHN, F. J. Sedimentary rocks. 3a ed. New York: Harper e row, 1975. 628 p.

RODRIGUES, M.; MAHIQUES, M. M. de; TESSLER, M. G. Sedimentação atual nas enseadas de Ubatumirim e Picinguaba, região norte de Ubatuba, Estado de São Paulo, Brasil. Revista

Brasileira de Oceanografia, São Paulo, v. 50, n. 1, p. 20-27, 2003.

ROMANKEVICH, E. A. Geochemistry of Organic Matter in the Ocean. New York, SpringerVerlag, 1984. 334 p.

SANTANA, N. M. G. de, PASSOS, P. F., MARACAJÁ, F. A. R., CUNHA, V. H. D., SILVA, J. B. da, TORRES, M. F. A. Distribuição Espaço Temporal e Uso e Ocupação dos Apicuns no Estuário de Itapessoca-PE. In: SIMPÓSIO NACIONAL DE GEOMORFOLOGIA, VIII, 2010, Pernambuco.

Anais... Recife, 2010.

SANTANA, N. M. G.; GALVÍNCIO, J. D.; TORRES, M. F. A.; OLIVEIRA, P. F. P.; SILVA, C. A. V.; SILVA, H. A.; CAVALCANTI, E. R. A.; TEIXEIRA, J. L.; PAZ, D. M.; SILVA, J. B.; LIRA, D. R. Distribuição Espaço Temporal do Ecossistema Manguezal no Estuário do Rio ItapessocaGoiana/PE. In: SIMPÓSIO BRASILEIRO DE SENSORIAMENTO REMOTO, 15. 2011, Curitiba. Anais... São José dos Campos: INPE, 2011. p. 6826-6834. Disponível em, http://urlib.net/3ERPFQRTRW/3A278B5. Acessado em 28 de jan. de 2012.

SANTOS, M. C. F. V.; ZIEMAN, J. C.; ARAÚJO, D. S. D. Hypersaline Intertidal Habitats on the Coast of Maranhão, Northern Brazil: An Introduction. Bol. Lab. Hibdro. São Luis, v. 9, p. 7387, 1996. 
OLIVEIRA, T. S.; BARCELLOS, R. L. Caracterização sedimentológica e geoquímica do apicum do sistema estuarino do Rio Itapessoca, Goiana - Pernambuco.

SANTOS, M. C. F. V. Apicuns, Salgados e Manguezais e a Ideologização do Debate sobre a Carcinicultura Marinha Brasileira. Rev. ABCC, v. 4, ano 7, 2005.

SCHAEFFER-NOVELLI, Y. Manguezal: ecossistema entre a terra e o mar. Caribbean Ecological Research. São Paulo: USP. 1995. 64 p.

Grupo de ecossistemas: Manguezal, Marisma e Apicum. 1999. 119 p.

SHEPARD, F. P. Nomenclature based on sand-silt-clay ratios. Journal Sedimentary Petrology, v. 24, p. 151-158, 1954.

SILVA, J. B. Estuário do Rio Itapessoca - Goiana/PE: Considerações Fisiográficas e Alternativas de Manejo. Recife, 2003. 99 f. Monografia (Graduação em Bacharelado em Geografia) - Departamento de Geografia. Universidade Federal de Pernambuco.

SIQUEIRA, R. L. Caracterização de uma Planície Hipersalina (Apicum) no Manguezal do Estuário do Rio dos Passos, Município de Rio Formoso, Pernambuco, Brasil. 2009. 45 f. Monografia (Especialização em Oceanografia) - Departamento de Oceanografia. Universidade Federal de Pernambuco.

STEIN, R. Accumulation of Organic Carbon in Marine Sediments: results from the Deep Sea Drilling Project/ Ocean Drilling Program (DSDP/ODP). In: BHATTACHARJI, S.; FRIEDMAN, G. M.; NEUGEBAUER, H. J.; SEILACHER, A. (Eds.), Lecture Notes in Earth Sciences. Berlin: Springer, v. 34, 217p. 1991.

SUGUIO, K. Introdução à sedimentologia. São Paulo: E. Blucher, 1973. 317 p. Geologia sedimentar. São Paulo: Edgard Blucher, 2003. 400 p.

SUSILO, A. Physical characteristics of sediment in the mangrove and salt flats. Jurnal Geofisika. Universitas Brawijaya Malang, 2005. Disponível em, http://elibrary.ub.ac.id/bitstream/123456789/18326/1/Physical-characteristics-of-sediment-inthe-mangrove-and-salt-flats.pdf. Acessado em 12 de dez. 2011.

UCHA, J. M.; HADLICH, G. M.; CELINO, J. J. Apicum: transição entre solos de encostas e manguezais. Educação, Tecnologia e Cultura, v. 5, p. 58-63, 2008. 